\title{
Surgery for Colorectal Cancer in Sri Lanka: Open to Laparoscopy
}

\author{
T. G. A. Priyantha \\ Teaching hospital, Colombo South, Sri Lanka
}

Keywords: Colorectal cancer; laparoscopy

\section{Introduction}

Colorectal cancer (CRC) is the third commonest cancer and the fourth most common cancer cause of death throughout the world with an estimated 1.2 million new cases and 600,000 deaths every year $[1,2]$. In Sri Lanka colorecatal cancer accounts for $7 \%$ of all malignancies with about 810 new cases diagnosed annually. It is the fourth commonest malignancy in males and fifth among females [3]

Traditionally, CRC was treated by open (conventional) surgery until Jacobs performed the first laparoscopic assisted colon cancer resection in 1991 [4]. The enthusiasm for laparoscopic colorectal resections for cancer suffered a setback when, in 1993, Alexander et al (4) reported the first case of wound recurrence three months after a right colectomy. Since 2002 four large RCTs have been published confirming the oncologic safety of laparoscopic compared with open colon cancer resection [5-8].

We performed the first laparoscopically assisted (LA) procedure for CRC in 2008 using basic laparoscopy instruments. In the beginning, most laparoscopic procedures that we undertook were laparoscopic assisted. However, as we gained experience and more advanced facilities were introduced, we progressed to perform total laparoscopic procedures (TL) for CRC.

The three main aims of our study were; to analyze the clinicopathological aspects of CRC in our patients, to assess our overall result of surgical treatment for $\mathrm{CRC}$, and to compare the surgical and oncologic outcomes between open and laparoscopic approaches for CRC in our patients.

\section{Materials and methods}

The study population comprised 270 patients managed by a single surgeon from August 1998 up to March 2016 at two tertiary care centers.

\footnotetext{
Correspondence: T. G. A. Priyantha

E-mail: amalpm2003@yahoo.com

Received: 20-03-2017 Accepted: 25-03-2018

(iD) http://orcid.org/0000-0001-5482-0408

DOI: http://doi.org/10.4038/sljs.v36i1.8475
}

\section{Definitions of access}

Open surgery: A procedure that was performed with a formal midline skin incision as planned.

Laparoscopic-assisted resection (LA) involved laparoscopic mobilization of the colon, visualization of critical structures, and standard total mesorectal excision (TME) for rectal cancer. A small transverse abdominal incision was required to complete the procedure for vascular ligation when 'haemolock' or vascular staplers were not available, and to remove the specimen.

Total laparoscopy (TL): For the purpose of this study TL was defined as where the entire procedure, except the intracorporeal anastomosis, was performed by the laparoscopic method.

Conversion is where the incision used was longer than a planned incision that was used to deliver the specimen in a laparoscopic procedure or where the incision was different to that planned.

\section{Surgical technique}

All procedures were performed according to standard techniques and lymph node dissection was carried out according to the "Guidelines and General Rules for Clinical and Pathological Studies on Cancer of the Colon, Rectum and Anus" by the Japanese Research Society for Cancer of the Colon and Rectum [9].

\section{Collection of data}

Data was collected from personally kept patient records, and operation records were analysed retrospectively. Pathology data were collected from the operation register maintained in the unit.

\section{Statistical analysis}

Categorical data are presented as percentage and compared by the chi-square test. Continuous data are presented as mean (standard deviation) and median (range). All analyses were performed using the SPSS software (SPSS Inc., Chicago, IL, USA). 


\section{Results}

Of 270 patients, 10 were excluded from the study (not operated $=6$, lost after neoadjuvant therapy $=1$, inadequate data $=3)$. Thus, data were analyzed in the remaining 260 patients; 159 male (59\%) and 111 female (41\%), median age 59 ; range 25 to 90 years.

\section{Clinico-pathological features}

\section{Aetiology:}

First degree relatives with a history of CRC were found among 8 patients $(\mathrm{n}=142 ; 5.6 \%)$. In 5 patients (3.5\%), CRC developed on a background of familial adenomatous polyposis (FAP) and two other patients (1.4\%) developed CRC in long standing ulcerative colitis.

\section{Presentation:}

Twenty eight patients $(n=175 ; 16 \%)$ presented with sub-acute intestinal obstruction. The mode of presentation in other patients is shown in Table1.

Duration of symptoms in 132 patients who were analysed varied from 1 to 24 months; median -3 months.

\section{Pathology:}

The site of distribution of cancers in 243 patients is shown in Table 2. Also, the composition in the stage of presentation of CRC over the 15-year period $(n=217)$ from 2001 is shown in Figure 1. Forty two of $252(17 \%)$ patients analysed had distant metastases at presentation. Histopathology data in 127 patients revealed well differentiated adenocarcinoma in 83 (65\%), moderately differentiated adenocarcinoma in 43 (34 $\%)$ and poorly differentiated adenocarcinoma in $1(1 \%)$ patient. There were 6(5\%) mucinous carcinomas.

Table 1. Mode of presentation

\begin{tabular}{|l|c|c|}
\hline \multicolumn{1}{|c|}{ Presentation } & Number & \% \\
\hline Bleeding per rectum & 75 & $42.8 \%$ \\
\hline Change of bowel habits & 30 & $17.1 \%$ \\
\hline Abdominal pain & 23 & $13.1 \%$ \\
\hline Anemia & 07 & $4 \%$ \\
\hline Other & 12 & $6.8 \%$ \\
\hline
\end{tabular}

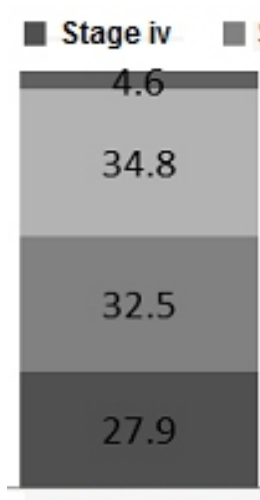

2001 to 20015

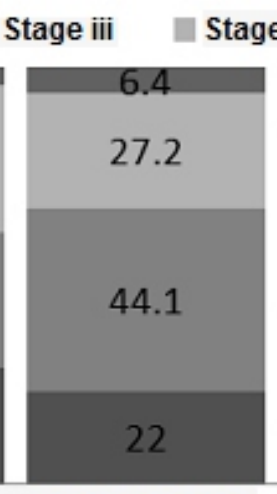

2006 to 2010

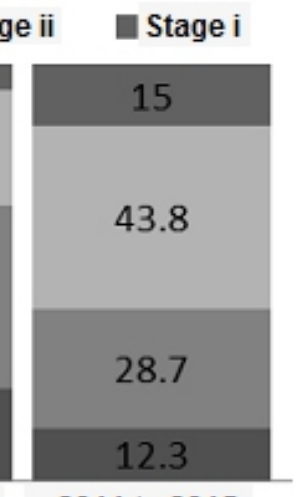

2011 to 2015
Figure 1. Tumour stage at presentation

\section{Surgical procedure:}

Two hundred and sixty patients had surgical intervention during the study period. Furthermore, 25 had only a palliative procedure (resectability 90\%), an emergency surgical procedure was required in $26(10 \%)$ patients for intestinal obstruction. In nine patients, tumour was not resectable.

Analysis of data from patients who underwent surgical resection $(n=235)$ showed that 66 patients were treated with neoadjuvant therapy. This includes 50 of 101 with rectal cancer (49\%) who received chemo irradiation, of which eight $(16 \%)$ were complete responders.

\section{Surgical access:}

One hundred and sixty-eight patients underwent open surgery (O) compared with 67 patients who underwent laparoscopic surgery. The laparoscopy group comprised 43 laparoscopic assisted (LA) and 24 total laparoscopic (TL) procedures. The overall conversion rate for laparoscopic procedures was $16 \%$.

\section{Surgical technique:}

Group I lymph nodes were included in the dissection (D1 dissection) in 32 patients and 143 patients underwent N2 nodal dissection (D2 dissection). Only 2 patients had N3 nodal (D3) dissection. In the remaining patients $(\mathrm{n}=58)$ nodal dissection status could not be determined (Dx).

To achieve tumour clearance combined organ resection was performed in 11 patients. A sutured colorectal anastomosis was performed in 73 patients $(51 \%)$ and stapled anastomosis was performed in 71 patients. In $27(34 \%)$ who underwent anterior resection of the rectum, we created a proximal diverting loop ileostomy.

\section{Quality indicators in surgical procedures:}

The AR: APR ratio was 1.5:1. The operating time for each procedure is shown in Table 3. Table 4 shows the volume of blood loss during the procedures.

All resected specimens $(n=235)$ had negative proximal and distal margins. The circumferential resection margin was reported only in later pathology reports and therefore the data were insufficient for analysis. Lymph node (LN) harvest could be determined in 92 patients $(36.5 \%)$. Twelve or more LNs were examined in $27 \%$ patients. The node positivity was $15 \%$. Table 5 indicates the lymph node harvest in 92 procedures. Also, the number of lymph nodes harvested in our unit has been increasing and had almost reached the recommended standard over the last two years (Figure 2)

\section{Post-operative complications:}

There were 93 complications (40\%), of which, thirteen (5.5\%) were major surgical complications. Seven of 185 patients had anastomotic leaks (4\%); five followed AR (leak rate following $\mathrm{AR}$ is $6.3 \%$ ). Other major complications were abdominal wound dehiscence $(\mathrm{n}=5 ; 2.1 \%)$ and post operative 


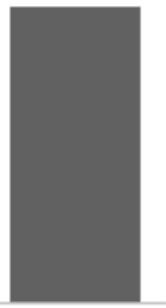

1998 - $20082009-20132014-2015$

Figure 2. Lymph node harvest-1998 to 2015

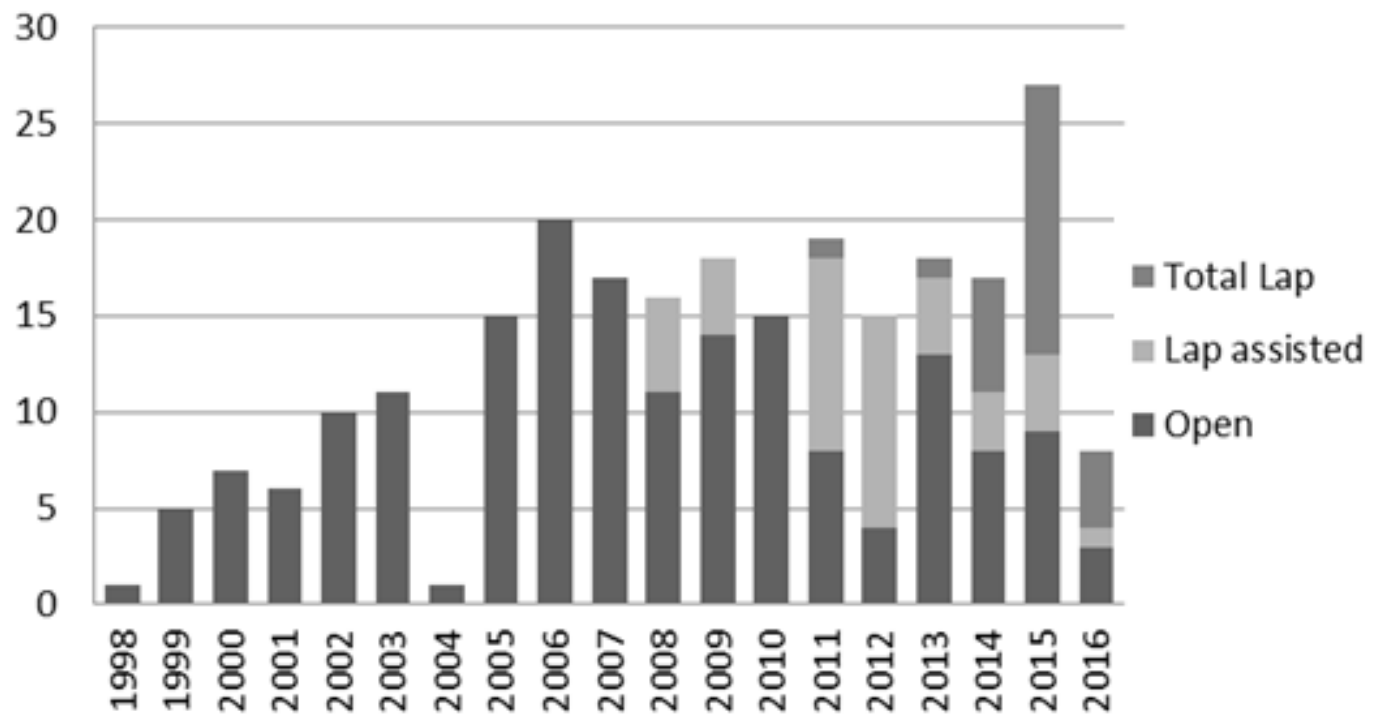

Figure 3. Transition from open to laparoscopic colorectal resection

Table 2. Distribution of Colorectal cancer

\begin{tabular}{|l|c|c|}
\hline Site & Number & \% \\
\hline Caecum & 03 & $1.2 \%$ \\
\hline Ascending Colon & 20 & $8.2 \%$ \\
\hline Transverse Colon & 18 & $7.4 \%$ \\
\hline Descending Colon & 09 & $3.7 \%$ \\
\hline Sigmoid Colon & 63 & $25.9 \%$ \\
\hline Recto sigmoid junction (Rs) & 24 & $10.2 \%$ \\
\hline Upper Rectum (Ra) & 32 & $13.1 \%$ \\
\hline Lower Rectum (Rb) & 66 & $27.1 \%$ \\
\hline
\end{tabular}

Table 3. Operating time (overall)

\begin{tabular}{|l|c|c|}
\hline \multicolumn{1}{|c|}{ Procedure } & $\begin{array}{c}\text { Range } \\
\text { (Hrs) }\end{array}$ & $\begin{array}{c}\text { Median } \\
\text { (Hrs) }\end{array}$ \\
\hline Right hemicolectomy $(n=11)$ & 1 to 4.5 & 2.2 \\
\hline Extended right hemicolectomy $(n=11)$ & 1.75 to 6.5 & 3 \\
\hline Left hemicolectomy $(n=8)$ & 2.5 to 4 & 2.7 \\
\hline Sigmoid colectomy $(n=32)$ & 2 to 4.5 & 2.7 \\
\hline Anterior resection (AR) $(n=68)$ & 2.5 to 6.5 & 4 \\
\hline Abdomino perineal resection (APR) $(n=36)$ & 2 to 7 & 4 \\
\hline Sub-total colectomy $(n=2)$ & 3.5 to 3.7 & 3.6 \\
\hline Procto-colectomy $(n=4)$ & 3.5 to 9 & 4 \\
\hline Hartmann's procedure $(n=9)$ & 1.5 to 4.5 & 2.5 \\
\hline
\end{tabular}


Table 4. Blood loss (overall)

\begin{tabular}{|l|c|c|}
\hline \multicolumn{1}{|c|}{ Procedure } & Range $(\mathbf{m l})$ & Median (ml) \\
\hline Right hemicolectomy $(n=18)$ & 50 to 700 & 275 \\
\hline Extended right hemicolectomy $(n=10)$ & 100 to 700 & 700 \\
\hline Left hemicolectomy $(n=08)$ & 50 to 500 & 325 \\
\hline Sigmoid colectomy $(n=46)$ & 100 to 2000 & 300 \\
\hline Anterior resection (AR) ( $n=37)$ & 300 to 3000 & 450 \\
\hline Abdomino-perineal resection (APR) ( $=37)$ & 300 to 3800 & 925 \\
\hline Subtotal colectomy ( $n=3)$ & 350 to 2000 & 650 \\
\hline Procto colectomy $(n=3)$ & 100 to 950 & 500 \\
\hline Hartmann's procedure $(n=8)$ & 50 to 500 & 275 \\
\hline
\end{tabular}

Table 5. Operative parameters open vs. laparoscopy

\begin{tabular}{|l|c|c|c|c|}
\hline \multicolumn{1}{|c|}{ Parameter } & Open & $\begin{array}{c}\text { Lap assisted } \\
\text { (LA) }\end{array}$ & $\begin{array}{c}\text { Total lap } \\
\text { (TL) }\end{array}$ & LA + TL \\
\hline Median operating time (hours) & $\begin{array}{c}3 \\
(1 \text { to } 6.5)\end{array}$ & $\begin{array}{c}4.6 \\
(3 \text { to } 9)\end{array}$ & $\begin{array}{c}4 \\
(2.5 \text { to } 5.5)\end{array}$ & $\begin{array}{c}4 \\
(2.5 \text { to } 9)\end{array}$ \\
\hline Median blood loss (ml) & $\begin{array}{c}500 \\
(50 \text { to } 3800)\end{array}$ & $\begin{array}{c}461 \\
(100 \text { to } 950)\end{array}$ & $\begin{array}{c}150 \\
(50 \text { to } 300)\end{array}$ & $\begin{array}{c}200 \\
\text { (50 to } 950)\end{array}$ \\
\hline $\begin{array}{l}\text { LN harvest (median) } \\
\text { (range) }\end{array}$ & 8.44 & 7.1 & 10.0 & 8.7 \\
\hline Conversion & $(1$ to 28$)$ & $(1$ to 15$)$ & $(3$ to 16$)$ & $(1$ to 16$)$ \\
\hline Median Hospital stay(d) & NA & \multicolumn{3}{|c|}{$12(17.9 \%)$} \\
& 8 & 8.1 & 5 & 5 \\
& $(4$ to 30$)$ & $(4$ to 38$)$ & $(3$ to 12$)$ & (3 to 38$)$ \\
\hline
\end{tabular}

Table 6. Cause of death

\begin{tabular}{|l|c|c|}
\hline \multicolumn{1}{|c|}{ Cause of death } & Number & $\%$ \\
\hline Sepsis & 04 & $1.7 \%$ \\
\hline Congestive cardiac failure & 02 & $0.8 \%$ \\
\hline $\begin{array}{l}\text { Deep vein thrombosis / Pulmonary } \\
\text { embolism }\end{array}$ & 01 & $0.4 \%$ \\
\hline Myocardial infarction & 01 & $0.4 \%$ \\
\hline Bleeding due to cirrhosis of liver / DIC* & 01 & $0.4 \%$ \\
\hline Hepato-renal syndrome & 01 & $0.4 \%$ \\
\hline Total & $\mathbf{1 0}$ & $\mathbf{4 . 2} \%$ \\
\hline
\end{tabular}

*Disseminated intravascular coagulation

bleeding $(\mathrm{n}=1 ; 0.4 \%)$. Wound infection occurred in 31 patients (13.1\%) and prolonged ileus was seen in $5(2.1 \%)$. Myocardial infarction (3.4\%) was the commonest nonsurgical post-operative complication (total 9.7\%). Twelve patients underwent re-exploration $(5 \%)$ and the hospital readmission rate was $2.5 \%$ (6 patients).

\section{Day post-operative mortality}

There were ten post-operative deaths (overall mortality of $4.2 \%)$. However, procedure related mortality was $1.7 \%$ ( $n=$ 4). All were due to sepsis following anastomotic leaks. The causes of death are listed in Table 6.

\section{Laparoscopic surgery}

Figure 3 illustrates the transition from open to laparoscopic procedures over the study period.
Open vs. laparoscopy:

Comparison of operative parameters between the two groups is shown in table 5. Respective percentages of morbidity, anastomotic leak and mortality for the open and laparoscopy groups were $31.1 \%$ versus $30.9 \%, 3.1 \%$ versus $2.9 \%$ and $5.5 \%$ versus $1.8 \%$.

\section{Intra operative complications:}

There were two intra operative complications in the laparoscopy group (3\%); inadvertent injury to bowel and injury to the left ureter.

\section{Follow up}

Follow up data was available for 121 patients (58\%). The overall follow up period ranged from to 2 months to 15 
years (median 1.1 years). An incisional hernia was found in 6 patients who underwent open surgery (4\%). Stoma complications were detected in 6 patients who underwent $\operatorname{APR}(15 \%)$.

\section{Oncological outcome (overall)}

\section{Local recurrence:}

There were 10 patients who developed local recurrences ( $8 \%$ ) from 2 to 49 months (median time to recurrence 1 year); nine followed surgery for rectal cancer $(n=80 ; 11 \%)$. Only one patient $(2.4 \%)$ developed local recurrence after colon cancer resection $(n=41)$. Nine local recurrences were following open $(10 \%)$ and 2 followed laparoscopic operation (6\%).

\section{Distant metastasis:}

Distant metastases were detected in 20 patients (17\%) during follow up. The commonest site was the liver. There was one port site $(1 \%)$ recurrence following a lap-assisted procedure at 9 months.

\section{Discussion}

This is a study of 260 patients with colorectal cancer who underwent either standard open or laparoscopic surgery. The median age of the study group was 59 years (range 25 to 90 years), which is lower than reported in most western literature (70 years, range 28 to 95) [10]. There was no marked difference in male to female ratio, 1.4: 1, in this study compared to other published data $[11,12]$.

\section{Clinico-pathological parameters}

Sixteen percent presented as an emergency. One study reported emergency presentation for CRC in $13.6 \%$ [10] whereas others have reported emergency presentations in up to $30 \%$ [13]. All patients who presented as an emergency had intestinal obstruction. Other larger studies have reported intestinal obstruction as the commonest $(78 \%)$ mode of emergency presentation $[14,15]$. Bleeding per rectum was the commonest symptom (42.8\%), which was followed by change of bowel habits $(17.1 \%)$ in those who presented to the out-patient clinic.

There is a marked variation in the duration of symptoms in developed countries ( 1 to 10 months; median 3.5 months) [16] and African countries (21 days to 84 months; median 22 months) [11]. In our study, median duration was 3 months (1 to 24 months).

A family history of CRC among first degree relatives was obtained in $8(5.6 \%)$ patients in this study and compares with the same reported by Phillipo LC (5.4\%) in his study of 332 patients from Tanzania [11]. In another study, a family history of CRC was reported among $20.5 \%$ of patients in Sweden [10]. Pooled data analysis shows a relative risk of $2.24 \%$ and $2.93 \%$ for patients with a first degree relative affected by CRC and patients with ulcerative colitis respectively [17].

In our study group the proportion of rectal cancer (RC) was higher $(40.2 \%)$ than reported (15.7 to $38.7 \%$ ) in other studies $[10,11,18]$. Further, about $80 \%$ of CRC in our patients was located on the left side making it accessible even with a flexible sigmoidoscope. Therefore, stool occult blood combined with flexible sigmoidoscopy would be an attractive option for screening of CRC in our patients. However, the cost effectiveness of this approach has to be determined by further studies.

Distant metastases were present at presentation in $16.6 \%$ of our patients with $80.9 \%$ of them in the liver and 4.6 in the lung. Published data shows 20 to $25 \%$ of colon cancer and 18 $\%$ of rectal cancer patients have distant metastases at presentation with liver being the commonest site [13].

\section{Preoperative management}

Neoadjuvant therapy has been used in 64 patients out of whom 50 were for patients with RC. The use of neoadjuvant chemoirradiation for $\mathrm{RC}$ became the standard practice after the trial in 2012 [19, 20]. Though $49 \%$ patients with RC received neoadjuvant therapy sub group analysis shows a marked increase in the tendency to use neoadjuvant therapy after the year 2011 (27\% before and $80 \%$ after 2011). Simon et. al. in 2012 [22], examined the trend in the use of neoadjuvant radiotherapy among surgeons across the south west region of France and found that $62 \%$ of the patients received neoadjuvant radiotherapy for RC. A complete response to neoadjuvant chemo radiation was seen in $16 \%$ of our patients. A similar response rate has been observed (17\%) in the landmark paper published in 2004 by Habr-Gama where they adopted a "watch and wait" policy for this group of complete responders [22]. Others have reported complete response rates as high as $25 \%$ [22].

\section{Surgery (overall)}

The overall operability among our patients (90\%) was lower than other studies (97\%) [19]. However, the operability among those patients undergoing emergency procedures was only $65 \%$, a finding that has not been reported earlier.

\section{Post-operative management}

The overall postoperative complication rate in this study $(39.5$ $\%)$ was higher than reported (26.2\%) in a similar study [11]. The commonest post-operative complication (13.2\%) was wound infection. The reported incidence of wound infection is between 3 to $30 \%$ across the literature [23]. Similarly, the overall incidence of anastomotic dehiscence $3.7 \%$ in this study) ranged between $1 \%$ to $30 \%$ in the literature $[24,25]$. Higher incidences of anastomotic dehiscence have been reported following rectal cancer resection versus colon resection (5\% vs. 10\%) [19]. However in the hands of an experienced colorectal surgeon, the reported incidence of 
anastomotic dehiscence following AR has been between 3\% and $6 \%[25]^{*}$, and it was slightly higher $(6.3 \%)$ in the present study. Prolonged ileus (2.1\%) contributed to longer hospital stay in our patients. One study showed a slight difference in the incidence of ileus following open surgery versus laparoscopic surgery (3.3\% vs. $2.4 \%$ ) but the difference was not statistically significant [26].

The median hospital stay was 10 days ( 3 to 38 days) in our patients. Median hospital stay after surgery for CRC was 12 (4 to 72 days) in one study [11]. The difference is probably due to the inclusion of patients who underwent laparoscopic surgery in our study. Our re-operation rate $(5.1 \%)$ was lower than the reported $12 \%$ for LA and $10 \%$ for open surgery [27]. The overall readmission rate of $2.5 \%$ in our study group is comparable to the reported $2 \%$ for LA and $12 \%$ for open surgery in the same study.

The overall 30 day mortality in our study was $4.2 \%$. Eighty percent of deaths followed surgery for rectal cancer. Mortality as high as $13 \%$ has been reported following emergency procedures while that reported for elective procedures is around $2 \%$ [19]. In these studies it is not clear if post-operative mortality was procedure related or due to other co morbid factors. Procedure related mortality in our patients was $1.7 \%$. Also, we observed higher mortality among patients with rectal cancer $(6.6 \%$ vs. $1.7 \%)$ than those with colon cancer. Others have reported overall mortality from $8 \%$ to $10.5 \%$ for CRC [11].

The number of LN examined could be determined in only 36.5 $\%$ of patients, far less than reported in other studies [28]. In a large study of 3557 patients mean LN harvest was 13 (1 to 53), (37); in our patients we could harvest only a median of 8 ( 1 to $41)$ nodes. Lymph node positive ratio (15.1\%) was also lower than reported $(49.7 \%)[18,29]$.

\section{Follow up}

Incisional hernias were found in $2.7 \%$ of patients followed up, and it was slightly higher than reported in the literature [26]. Port site hernia was observed in $1.4 \%$ of the patients by the same group but we have not encountered this complication in our patients undergoing laparoscopy thus far. Port site recurrence was seen in one of our patients (1.4\%). In one study port site recurrence following laparoscopic resection of CRC was $1.2 \%$ [30]. Other studies have reported port site recurrences between 0.7 to $1.3 \%$ following laparoscopic surgery for CRC $[5,31]$. The complications related to stoma in our study $(14.6 \%)$ was also higher than that reported in a similar study (4.1\%) [27].

\section{Oncological outcome}

The literature reveals a higher local recurrence rate for $\mathrm{RC}(10$ to $20 \%$ ) compared to colon cancer ( 2 to $10 \%$ ) [26]. In our patients, local recurrences were seen in $11.2 \%$ following RC and $2.4 \%$ following colon cancer (overall $8.2 \%$ ) and was within the reported figures. In a meta-analysis, 40 to $50 \%$ of patients eventually developed liver secondaries following surgery for CRC within 3 years [32]. In our study $10.7 \%$ of the patients developed liver secondaries within 2 years. The incidence of brain metastases among our patients (1.6\%) was within the reported range of $0.6 \%$ to $3.2 \%$ [33].

\section{Open surgery vs. Laparoscopy}

The operative time in the laparoscopy group (LA + TL) was longer than the open surgery group. In a meta-analysis of 13 trials operating time in laparoscopy was longer $(p=0.027)$ in all but one (32) study. In addition, most of the studies have observed significantly lower mean blood loss following the laparoscopic approach [34]. Though our blood losses in both groups were higher (689 ml vs. $323 \mathrm{ml}$ ) laparoscopy group had a lower blood loss). The two intraoperative complications $(2.9 \%)$ were seen within in the first 10 procedures. In most studies, the incidence of intraoperative complications were similar in laparoscopic (for RC 6.1\% to $21.1 \%$ : overall $3.7 \%$ ) and open surgery [35].

Conversion rate in our study $(17.9 \%)$ was almost equal to that reported from North America (17.5\%) although it is higher than the Europe (10.3\%) and Asia (13.6\%) [36]. However, it is within the reported range (15 to $30 \%)[6,8,37,38]$. The reported hospital stay after laparoscopic CRC surgery is 5 to 8 days $[6,8]$. In a meta-analysis of 7 trials, hospital stay after laparoscopic colon and rectal cancer resection has been analyzed separately and shown to be significantly shorter in both groups [35]. In our study the hospital stay was assessed together in both groups and was found to be lower in laparoscopy group (open 9.4 days vs. laparoscopy 6.1 days).

Postoperative complications in our study were comparable between the two groups (open 31\% vs. laparoscopy 30.9\%). The literature does not reveal a significant difference in postoperative complications between laparoscopic and open surgery either [35]. Anastomotic leak rate did not differ significantly between the two groups (OR 0.97) in this study. However in most published studies, including a meta-analysis of 7 trials [35], there was no significant difference in the anastomotic leakage between open and laparoscopic approach. There was no significant difference in postoperative mortality between the open and laparoscopic techniques $(5.5 \%$ vs. $1.8 \%$; OR 0.25$)$. In a meta-analysis of six trials, mortality was below $2 \%$ in either group [35]. Though not statistically significant, open surgery group in our study showed a higher mortality $(5.5 \%)$ probably because of the inclusion of the learning curve. In another randomized trial mortality was $5 \%$ for open and $4 \%$ for laparoscopic surgery [39].

Higher LN harvest in TL group could be attributed to the difference in pathological reporting rather than the surgical 
technique since this group represents the most recently reported group where LN harvesting is highest.

Local recurrence after the resection of colon cancer was $28 \%$ vs. $18 \%$ in the Barcelona trial [34]. In our study local recurrence following open surgery $(10.2 \%)$ was lower than Barcelona trial. Though local recurrence following laparoscopic resection was lower in our study ( $6 \%$ ) compared with Barcelona trial, comparison cannot be made since ours is not a randomized controlled trial. Multiple factors would have contributed for the higher local recurrence rate in open surgery group. Some of the patients especially in the early part of this study did not receive neoadjuvant therapy as they underwent surgery in an era before the neo adjuvant therapy became the standard practice at least in our practice (use of neoadjuvant therapy for RC was $27 \%$ before and $80 \%$ after 2011). Secondly, the learning curve also would have contributed to some extent. Thirdly, patients who underwent laparoscopic surgery have been followed up for a shorter period compared to open surgery group. Many randomized studies have confirmed the non-inferiority of laparoscopic over open surgery with respect to overall survival and diseasefree survival $[, 3,14$, , 40]. Our experience is similar despite being a non-randomized study.

\section{Conclusion}

There are differences in the clinic-pathological aspects of $\mathrm{CRC}$ in our patients especially with regard to age and stage at presentation. The overall operative and oncological result of this study shows that we can reach the accepted standards in colorectal surgery. Though laparoscopic surgery for colorectal cancer is more recent, despite the steep learning curve we have reached accepted international standards within a short period of time. Two aspects of our study that need attention are LN retrieval and reporting, and long term follow up. While LN harvest has shown improvement over the years, follow up reporting of patients has to be longer.

All authors disclose no conflict of interest. The study was conducted in accordance with the ethical standards of the relevant institutional or national ethics committee and the Helsinki Declaration of 1975, as revised in 2000 .

\section{References}

1. Brenner H, Kloor M, Pox CP. Colorectal cancer. Lancet. 2014 Apr 26;383 (9927):1490-502. https://doi.org/10.1016/S0140-6736(13)61649-9

2. Hermann Brenner, Metthias Kloor, Christian Peter Pox. Colorectal cancer. Lancet, 2014 :383, 1490-502 https://doi.org/10.1016/S0140-6736(13)61649-9

3. Cancer Incidence Data, 2007 : National Cancer Control Programme,Sri Lanka.

4. Alexander RJ, Jaques BC, Mitchell KG. Laparoscopically assisted colectomy and wound recurrence. Lancet 1993; 341: 249-250. 4

5. Lacy AM, Garcia-Valdecasas JC, Delgado S, et al. Laparoscopyassisted colectomy versus open colectomy for treatment of non- metastatic colon cancer: a randomised trial. Lancet. 2002;359:2224-9.

https://doi.org/10.1016/S0140-6736(02)09290-5

6. The Clinical Outcomes of Surgical Therapy Study Group (COST). NEngJ Med,2004 :350; 20,2050-58.

https://doi.org/10.1056/NEJMoa032651

7. Martijn HGM van der Pas, MD, Prof Eva Haglind, MD, Prof Miguel A Cuesta, MD, Prof Alois Fürst MD, Prof Antonio M Lacy, MD, Wim CJ Hop, PhD, Prof Hendrik Jaap Bonjer, MD. Laparoscopic versus open surgery for rectal cancer (COLOR II): short-term outcomes of a randomised, phase 3 trial. Lancet Oncol. 2013 Mar;14(3):210-8. https://doi.org/10.1016/S1470-2045(13)70016-0

8. Guillou PJ, Quirke P, Thorpe H, Walker J, Jayne DG, Smith AM, Heath RM, Brown JM. Short-term endpoints of conventional versus laparoscopic-assisted surgery in patients with colorectal cancer (MRC CLASICC trial): Multicentre, randomised controlled trial. Lancet 2005;365:1718-1726. https://doi.org/10.1016/S0140-6736(05)66545-2

9. Japanese Classificationof Colorectal carcinoma in Japanese Sosiety for Cancer of the Colon and Rectm. KANEHARA \& CO., LTD., TOKYO, 1997.

10. Sam Ghazi et al. Clinicopathological analysis of colorectal cancer: a comparison between emergency and elective surgical cases. World Journal of Surgical Oncology 2013, 11:133, 2-11.

11. Phillipo L Chalya et al. Cilnico-pathological patterns and Challenges of management of colorectal cancer in a resource -limited setting- Tanzanian experience. World Journal of Surgical Oncology 2013, 11:88, 3-9.

12. Monica Millan, Sandra Merino, Aleidis Caro, Francesc Feliu, Jordi Escuder, Tani Francesch. Treatment of colorectal cancer in the elderly. World J Gastrointest Oncol 2015 October 15; 7(10): 204-220.

https://doi.org/10.4251/wjgo.v7.i10.204

13. Marina De Rosa. Genetics, diagnosis and management of colorectal cancer (Review). ONCOLOGY REPORTS, 2015 : 34: 1087-1096.13

14. Metcalfe MS et Al. Unreasonable expectations in emergency colorectal cancer. Colorectal Dis, 2005 : 7 (3), 275-278. https://doi.org/10.1111/j.1463-1318.2005.00784.x

15. Wong SK et Al. Tumor pathology and long-term survival in emergency colorectal cancer. Dis Colon Rectum, 2008 :51 (2), 223-230.

https://doi.org/10.1007/s10350-007-9094-2

16. Majumdar SR1, Fletcher RH, Evans AT. How does colorectal cancer present? Symptoms, duration, and clues to location. Am J Gastroenterol. 1999 Oct;94(10):3039-45. https://doi.org/10.1111/j.1572-0241.1999.01454.x

17. Constance M. Johnson, Caimiao Wei, [...], and Donald A. Berry Meta-analyses of Colorectal Cancer Risk.

18. Jan H. Wong, MD; D. Scott Johnson, MD; Daphne Hemmings, MD; Andrew Hsu, MD; Taryne Imai, BS; Gail T. Tominaga, MD. Assessing the Quality of Colorectal Cancer Staging: Documenting the Process in Improving the Staging of NodeNegative Colorectal Cancer. Arch Surg. 2005;140:881-887. https://doi.org/10.1001/archsurg.140.9.881

19. Simone Mathoulin-Pélissier et al. Quality indicators for colorectal cancer surgery and care according to Patient-, tumor-, and hospital related factors. BMC Cancer 2012, 12:297, 3-10.

20. Eva J A Morris, Nicola J Maughan, David Forman, et al. Who to treat with adjuvant therapy in Dukes B/stage II colorectal cancer? The need for high quality pathology. Gut, 2007 56: 1419-1425. https://doi.org/10.1136/gut.2006.116830

21. Habr-Gama A, Perez RO, Nadalin W, Sabbaga J, Ribeiro U, Silva e Sousa AH, Campos FG, Kiss DR, Gama-Rodrigues J. Operative 
versus nonoperative treatment for stage 0 distal rectal cancer following chemoradiation therapy: long-term results. Ann Surg 2004; 240: 711-717.

https://doi.org/10.1097/01.sla.0000141194.27992.32

22. Brian D P O'Neill, Gina Brown, R J Heald, David Cunningham, Diana M Tait. Non-operative treatment after neoadjuvant chemoradiotherapy for rectal cancer. oncology. Lancet, $2000: 8$, 625-32.

23. Roboerto Biffi et al. surgical site infections following colorectal cancer surgery: a randomized prospective trial comparing common and advanced antimicrobial dressing containing ionic silver. World Journal of Surgical Oncology 2012, 10:94. https://doi.org/10.1186/1477-7819-10-94

24. Jeonghyun Kang et al. Multicenter Analysis of long-Term Oncologic Impact of Anastomotic Leakage after laparoscopic Mesorectal Excision. Medicine, 2015; 94 (29),1-8.

25. T Peter Kingham, H Leon Pachter. Colonin Anastomotic leal : Risk Factors, Diagnosis and Treatment. J Am Coll Surg, 2009 : 208 (2), 269- 76. https://doi.org/10.1016/j.jamcollsurg.2008.10.015

26. Antonio Biondi et al. Laparoscopic-Assisted Versus Open Surgery for Colorectal Cancer: Short- and Long-Term Outcomes Comparison. Journal of Laparoendoscopic \& advanced Surgical techniques, $2013: 23$ (1), 1-7. https://doi.org/10.1089/lap.2012.0276

27. Fazli C Gezen, MD; Erman Aytac, MD; Meagan M Costedio, MD; Jon D Vogel, MD; Emre Gorgun, MD. Hand-Assisted versus Straight-Laparoscopic versus Open Proctosigmoidectomy for Treatment of Sigmoid and Rectal Cancer: A Case-Matched Study of 100 Patients Perm J2015 Spring;19(2):10-14.

28. Nancy N. Baxter, Dan J. Virnig, David A. Rothenberger, Arden M. Morris, Jose Jessurun, Beth A. Virnig . Lymph Node Evaluation in Colorectal Cancer Patients: A Population-Based Study. Journal of the National Cancer Institute, 2005 : 97(3), 219-25. https://doi.org/10.1093/jnci/dji020

29. T.E. Le Voyer, E.R. Sigurdson, A.L. Hanlon, R.J. Mayer, J.S. Macdonald, P.J. Catalano, and D.G. Haller. Colon Cancer Survival Is Associated With Increasing Number of Lymph Nodes Analyzed: A Secondary Survey of Intergroup Trial INT-0089. Journal of Clinical Oncology,2003 : 21, (15), 2912-2919. https://doi.org/10.1200/JCO.2003.05.062

30. Jing Sun, Tao Jiang, Zhengjun Qiu, Gang Cen, Jun Cao, Kejian Huang, Ying $\mathrm{Pu}$, Hong Liang, Renxiang Huang, Shifu Chen. Short-term and medium-term clinical outcomes of laparoscopicassisted and open surgery for colorectal cancer: a single center retrospective case-control study. BMC Gastroenterology 2011,
11:85,1-12. https://doi.org/10.1186/1471-230X-11-85

31. Liang JT, Huang KC, Lai HS, et al. Oncologic results of laparoscopic versus conventional open surgery for stage II or III left-sided colon cancers: a randomized controlled trial. Ann Surg Oncol. 2007;14:109-17.

https://doi.org/10.1245/s10434-006-9135-4

32. Mélanie Morneau et al. Laparoscopic versus open surgery for the treatment of colorectal cancer: a literature review and recommendations from the Comité de l'évolution des pratiques en oncologie. Can J Surg. 2013 Oct; 56(5): 297-310.

https://doi.org/10.1503/cjs.005512

33. Troels Dreier Christensen, Karen-Lise Garm Spindler, Jesper Andreas Palshof, Dorte Lisbet Nielsen. Systematic review: brain metastases from colorectal cancer-Incidence and patient characteristics. BMC Cancer, 2016: 16:260, 2-14.

34. Bruno Andreoni et al. Surgical outcomes of colon and rectal cancer over a decade; results from consecutive 902 unselected patients. Wold JOnco Surg,2007 : 5; 73, 1-10.

35. Lujan J, Valero G, Hernandez Q, et al. Randomized clinical trial comparing laparoscopic and open surgery in patients with rectal cancer. BrJ Surg. 2009;96:982-9.

https://doi.org/10.1002/bjs.6662

36. J Key Noel et al. Minimally Invasive Colorectal Resectio Outcomes: Short-term Comparison with Open procedures. J Am Coll Surg, 2007 :204 (2),291-306. https://doi.org/10.1016/j.jamcollsurg.2006.10.002

37. Li JC, Leung KL, Ng SS, Liu SY, Lee JF, Hon SS. Laparoscopicassisted versus open resection of right-sided colonic cancer-A prospective randomized controlled trial. Int $J$ Colorectal Dis 2012;27:95-102.

https://doi.org/10.1007/s00384-011-1294-5

38. Veldkamp R, Kuhry E, Hop WC, Jeekel J, Kazemier G, Bonjer HJ, Haglind E, Pahlman L, Cuesta MA, Msika S, Morino M, Lacy AM. Laparoscopic surgery versus open surgery for colon cancer: Short-term outcomes of a randomised trial. Lancet Oncol 2005;6:477-484. https://doi.org/10.1016/S1470-2045(05)70221-7

39. Buunen M, Veldkamp R, Hop WC, et al. Survival after laparoscopic surgery versus open surgery for colon cancer: longterm outcome of a randomised clinical trial. Lancet Oncol. 2009; 10:44-52. https://doi.org/10.1016/S1470-2045(08)70310-3

40. Bärlehner E, Benhidjeb T, Anders S, Schicke B. Laparoscopic resection for rectal cancer: outcomes in 194 patients and review of the literature. Surg Endosc. 2005 Jun;19(6):757-66.

https://doi.org/10.1007/s00464-004-9134-0 